\title{
EDUTECH
}

\section{IMPLEMENTASI GAMIFIKASI SEBAGAI MANAJEMEN PENDIDIKAN UNTUK MOTIVASI PEMBELAJARAN}

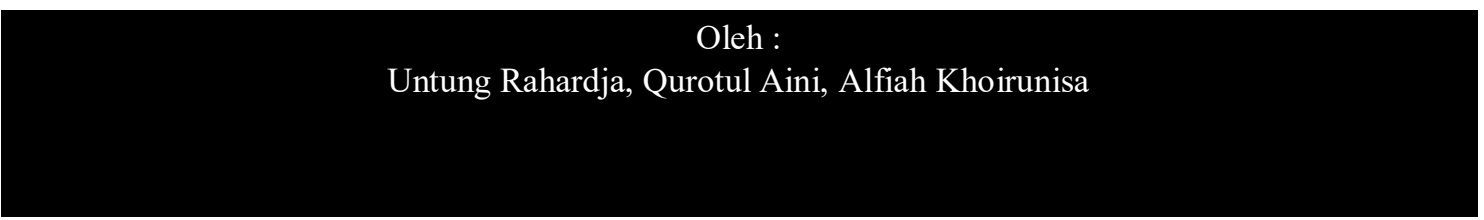

Abstrack. As we know now, Indonesia has begun to enter the era of revolution 4.0 which in that era had a lot of changes in all fields. Including in the field of education, the changes that occur in the world of education today are so significant with the abandonment of teaching methods that still use conventional methods. Track tasks with books, face-to-face communication, collect hard copy assignments, which of course will cause a lot of losses in a certain period of time, like many long-stored tasks that are hard to find when needed. Learning methods are considered a boring way, where students cannot explore learning searches for the number of files that have been collected. So from now on the application of learning methods is done with the concept of gamification. Gamification learning methods are made to follow the era when students prefer to play games rather than learning, therefore the gamification method can be applied to management of education at a higher level of education. It is hoped that this method can increase students' interest in learning so that it motivates to explore abilities in the learning process.
Informasi Artikel :

Artikel diterima 4 Januari 2019

Perbaikan 25 Januari 2019

Diterbitkan 14 Februari 2019

Terbit Online 15 Febuari 2019

Kata kunci: Revolution 4.0 Gamification, Education

\section{A. PENDAHULUAN}

Sistem belajar mengajar yang berjalan di dalam sebuah instansi pendidikan, memiliki peran penting dalam proses pembentukan pola pikir dan kreativitas dalam pribadi mahasiswa. Metode pembelajaran yang saat ini berjalan pada beberapa perguruan tinggi di Indonesia, saat ini masih menggunakan cara konvensional dalam proses belajar dan mengajar yaitu dengan menggunakan kertas sebagai media pengerjaan tugas yang diberi- kan oleh dosen, berdiskusi di kelas secara langsung, mengumpulkan tugas dengan memberikan lembaran tugas kepada dosen, yang berkelanjutan terus menerus setiap harinya. Tentunya dengan menggunakan metode seperti itu pada era revolusi 4.0 atau era disruptif saat ini akan sangat terasa jenuh sehingga mahasiswa akan menjadi malas dan tidak mau melakukan eksplorasi pada proses pembelajaran. Dengan demikian akan mengakibatkan mahasiswa menjadi lebih berkemDOI: https://doi.org/10.17509/e.v18i1.14697 
bang namun akan semakin tertinggal dalam proses pembelajaran. Pihak instansi pendidikan atau lebih tepatnya perguruan tinggi harus melihat dampak tersebut agar bobot mahasiswa ketika lulus nanti memiliki bekal didunia kerja.

Saat ini, dengan masih diterapkannya metode pembelajaran yang monoton membuat mahasiswa lebih mudah stress dan jenuh, sehingga tidak banyak mahasiswa memilih untuk bermain game sebagai sarana melampiaskan rasa jenuh dan stress yang dirasakan. Karena dapat dibuktikan ketika seseorang sudah bermain game dapat memperbaiki perasaan mahasiswa. Dengan hal tersebut berbagai perguruan tinggi di Indonesia gencar mencari metode pembelajaran yang tidak membosankan dan membuat mahasiswa turut aktif dan antusias dalam mengikuti proses pembelajaran. Maka tercetuslah sebuah metode pembelajaran yang mengadaptasi dari elemen-elemen yang terdapat dalam sebuah game yaitu metode gamifikasi. Metode gamifikasi pada manajemen edukasi merupakan sebuah metode pembelajaran baru dengan mengadaptasi dari elemen-elemen karakteristik dalam game yang dapat meningkatkan motivasi mahasiswa dalam proses

No. SK Akreditasi Ristekdikti : 34/E/KPT/2018 pembelajaran. Sehingga mahasiswa yang merasa jenuh dengan metode pembelajaran yang telah diterapkan sebelumnya dapat meningkat semangat belajarnya dengan fitur-fitur game yang diterapkan dalam metode pembelajaran gamifikasi seperti, pemberian reward, dan kuis interaktif akan menambah semangat mahasiswa dan memotivasi untuk meningkatkan eksplorasi pada proses pembelajaran yang nantinya akan meningkatkan produktivitas mahasiswa tentunya. Pihak instansi pendidikan atau perguruan tinggi juga mendapatkan manfaatnya dengan meningkatnya proses pembelajaran yang sebelumnya terasa monoton, dan akan menghasilkan lulusan-lulusan yang memiliki wawasan yang luas serta berbobot sebagai bekal di dunia kerja nantinya.

The philosopher Wittgenstein defines a game as "a range of disparate human activities that bear to one another only what one might call family resemblances" cited by Erenli (2013)

Menurut Takashi (2010) dalam penelitian yang dilakukan oleh Sitaresmi Wahyu Handani dkk (2016), Gamifikasi adalah sebuah proses yang bertujuan mengubah konteks nongame (contoh: belajar, mengajar, 
pemasaran, dan lain sebagainya) menjadi jauh lebih menarik dengan mengintegrasikan game thinking, game design, dan game mechanics.

Menurut penelitian yang dilakukan Acun Kardianawati dkk (2015) gamifikasi adalah penerapan dan penggunaan elemen desain game ke dalam konteks nongame. Sedangkan penelitian yang dilakukan Endra Murti Sagoro (2016) mengemukakan gamifikasi adalah aplikasi dinamis berbasis permainan dalam rangka mengedukasi .

Gamification has been defined as a process of enhancing services with (motivational) affordances in order to invoke gameful experiences and further behavioural outcomes. (Hamari, 2013)

Lalu menurut pendapat yang dikemukakan oleh Supriyanto dalam penelitiannya pada tahun (2017) Gamifikasi adalah suatu pendekatan penerapan komponen dan mekanisme game/permainan dalam sistem yang tidak berbasis permainan .

Dari beberapa pengertian gamifikasi diatas dapat penulis simpulkan bahwa gamifikasi adalah sebuah metode yang menggunakan elemen komponen dalam sebuah permainan yang diterapkan ke dalam sebuah sis- tem yang sebelumnya bersifat konteks non-game

Digital gaming is now pursued by a majority of the first world population. The age range of gamers gets younger every year while veteran gamers continue to play well beyond childhood, (Arnold, 2014).

Penelitian ini menggunakan pendekatan kualitatif yaitu dengan memberikan makna secara mendalam terhadap fakta atau data yang ada. Pendekatan tersebut digunakan karena penelitian ini bertujuan untuk mendeskripsikan atau menjelaskan data dan fakta dari kondisi yang ada, serta melakukan analisa mengenai hal apa saja yang harus dilakukan untuk mencapai kondisi yang diinginkan dalam waktu yang akan datang.

Metode yang digunakan pada penelitian ini yakni metode penelitian deskriptif yaitu metode penelitian yang menjelaskan sebuah objek sesuai dengan kondisi yang ada tanpa mengubahnya. Dalam penelitian ini penulis akan menjelaskan bagaimana efektifitas metode pembelajaran dengan gamifikasi pada manajemen edukasi di era industri 4.0 saat ini. Dari deskripsi yang sederhana, diharapkan penelitian ini dapat dikembangkan dan diterapkan agar sistem manajemen pada pen- 
didikan tinggi yang ada di indonesia saat ini dapat beradaptasi dengan era industri 4.0 saat ini dan tidak kalah saing dengan bidang lainnya.

Dalam penelitian ini peneliti menetapkan tempat penelitian di Perguruan Tinggi Raharja. Objek yang menjadi penelitian ini yaitu metode pembelajaran yang sedang digunakan saat ini untuk menunjang era industri 4.0. Keseluruhan informasi yang peneliti dapatkan pada penelitian ini dikumpulkan dari beberapa sumber, yaitu manusia, sistem yang berjalan dan penerapannya.

Dalam memilih dan menentukan sumber dari data tersebut menggunakan prosedur purposive sampling. Ditempuhnya prosedur tersebut dan teknik sampling itu didasari atas dasar pemikiran bahwa sampling pada penelitian kualitatif merupakan pilihan peneliti tentang aspek apa saja dari peristiwa yang terjadi dan siapa yang menjadi fokus penelitian pada situasi tertentu, dan maka dari itu dilakukannya penelitian yang terus menerus sesuai dengan pendekatan yang digunakan. Maka, instrumen yang peneliti gunakan untuk mengumpulkan data adalah peneliti sendiri sebagai key instrument atau alat penelitian utama yang cukup penting dengan menggunakan beberapa teknik pengumpulan data yaitu, wawancara, observasi dan studi pustaka .

Proses analisa data yang dilakukan oleh peneliti melalui tahapan sebagai berikut : 1) melakukan koreksi terhadap data yang didapatkan ketika melakukan observasi. 2) melakukan pengelompokkan data supaya mudah dalam mengambil kesimpulan nantinya . 3) memberikan kode pada data yang sudah ada guna untuk memudahkan mengidentifikasinya. Analisa data yang dilakukan adalah sebagai berikut, yaitu reduksi data, penyampaian data serta penyimpulan dan verifikasi.

Dalam sebuah penelitian pastilah ada tujuan yang ingin dicapai. Tujuan dari penelitian ini adalah untuk melihat pengaruh diterapkannya metode gamifikasi pada manajemen edukasi untuk meningkatkan keaktifan serta memotivasi minat belajar mahasiswa. Karena dengan menggunakan metode belajar konvensional masih belum efektif untuk meningkatkan minat belajar dan keaktifan seorang mahasiswa dalam proses pembelajaran sehingga diperlukannya metode alternatif dengan mengikuti perkembangan zaman pada era disrupsi saat ini.

DOI: https://doi.org/10.17509/e.v18i1.14697 
Proses belajar sebelum memasuki era industri 4.0 masih menggunakan metode pembelajaran secara konvensional, sehingga membuat minat belajar mahasiswa pada saat itu masih tergolong semangat dalam proses pembelajaran. Namun ketika sudah memasuki era industri 4.0 dimana perkembangan teknologi informasi sangat pesat membuat mahasiswa semakin mengurangi minat belajar mahasiswa dengan metode pembelajaran yang masih konvensional. Saat ini dengan adanya Internet membuat semakin berkurangnya minat belajar mahasiswa sehingga jarang mengerjakan tugas-tugas yang diberikan oleh dosen. Setelah pesatnya perkembangan teknologi ditambah adanya internet saat ini, beberapa game membuat mahasiswa lebih cenderung tertarik dengan gadget yang dimilikinya tanpa memperdulikan kegiatan belajar yang berlangsung. Terbukti dengan saat berlangsungnya kegiatan belajarmengajar hanya sedikit mahasiswa yang memperhatikan pada saat dosen menerangkan materi di kelas dan tidak sedikit mahasiswa yang lebih tertarik dengan gadget, sehingga ketika dosen memberikan tugas tidak sedikit dari mahasiswa yang terlewat dalam menerima informasi.

No. SK Akreditasi Ristekdikti : 34/E/KPT/2018
Hal tersebut didasari oleh rasa jenuh, dikarenakan proses belajar mengajar yang masih konvensional, yakni dengan masuk kelas, dosen menerangkan dan memberikan tugas, lalu mengumpulkan tugas membuat suasana pembelajaran terasa monoton atau membosankan. Hal inilah yang membuat manajemen pendidikan pada sebuah instansi pendidikan tinggi tidak akan bisa beradaptasi dengan era industri 4.0 dan akan kalah dengan instansi pendidikan lainnya yang jauh lebih siap untuk menyongsong era industri 4.0 ini .

Permasalahan tersebut sudah dilihat oleh Perguruan Tinggi Raharja sehingga membuat suatu inovasi pembelajaran secara iLearning dengan memanfaatkan iDu (iLearning Education), iMe (iLearning Media) serta Rinfo dalam metode pembelajaran yang dipakai. Namun dengan menggunakan metode tersebut dinilai masih belum bisa meminimalisir tingkat minat belajar mahasiswa yang rendah disebabkan masih berlangsungnya proses pembelajaran tatap muka ketika perkuliahan berlangsung yang dapat dianggap kurang memotivasi mahasiswa.

Menurut penelitian yang dilakukan oleh Untung Rahardja, Khanna

DOI: https://doi.org/10.17509/e.v18i1.14697 
Tiara, dan Ray Indra Taufik Wijaya (2014), Rinfo adalah email resmi yang digunakan oleh Perguruan Tinggi Raharja sebagai media komunikasi sekaligus alat bantu dalam proses pembelajaran yang memungkinkan untuk mengirim dan menerima email dari luar (external) .

Sedangkan menurut penelitian yang dilakukan oleh Ary Budi Warsito dkk (2014) Rinfo adalah sebuah layanan gmail menggunakan platform google yang disediakan khusus oleh Perguruan Tinggi Raharja untuk Pribadi Raharja .

Lalu menurut Untung Rahardja, Indri Handayani, dan Rizki Afri Liani Firmansyah dalam penelitiannya pada tahun (2016) Rinfo adalah media komunikasi sekaligus alat pendukung dalam proses pembelajaran di Perguruan Tinggi Raharja .

Dari beberapa pengertian perihal Rinfo diatas dapat penulis simpulkan kalau Rinfo merupakan sebuah layanan email menggunakan platform google yang disediakan khusus oleh Perguruan Tinggi Raharja untuk Pribadi Raharja .

Menurut penelitian yang dilakukan oleh Untung Rahardja, Muhammad Yusup dan Qurotul Aini (2014) iDu atau iLearning Education

No. SK Akreditasi Ristekdikti : 34/E/KPT/2018 merupakan media pembelajaran online guna mendukung pembelajaran konvensional. iDu (iLearning Education) merupakan salah satu dari Sepuluh Pilar iLearning yang memanfaatkan ICT yang dikembangkan oleh Perguruan Tinggi Raharja secara Online menggunakan Learning Management System (LMS) cloud-hosted tanpa perlu menginstall atau mendownload untuk memudahkan civitas kampus dan mahasiswa dalam menjalankan perkuliahan.

Menurut Untung Rahardja, Sudaryono dan Irwan Nurdin (2014) dalam penelitiannya menyebutkan iMe (iLearning Media) merupakan sebuah official portal blogging yang dipersembahkan khusus untuk Pribadi Raharja, dan setiap Pribadi Raharja akan mendapatkan subdomain sebagai media dokumentasi segala bentuk aktivitas Tridharma.

Dari permasalahan tersebut dapat dijadikan solusi bagaimana menambahkan minat belajar mahasiswa dengan menggabungkan beberapa elemen diatas. Salah satunya dengan menerapkan gamifikasi pada metode pembelajaran iLearning. Dengan demikian minat belajar mahasiswa dapat bertambah secara perlahan .

PENYELESAIAN MASALAH

DOI: https://doi.org/10.17509/e.v18i1.14697 
Pada permasalahan yang telah diangkat di atas, bagaimana caranya agar meningkatnya motivasi mahasiswa pada proses pembelajaran. Karena tujuan utama dari pendidikan tinggi adalah untuk menambah atau mengembangkan ilmu pengetahuan yang didapatkan sebelumnya serta untuk mengembangkan bidang minat mahasiswa. Namun karena berkurangnya minat dan motivasi belajar mahasiswa, tujuan utama dari pendidikan tinggi perlahan semakin sirna. Maka dari itu elemen gamifikasi atau elemen game diterapkan pada sistem perkuliahan di Perguruan Tinggi Raharja, dimana dengan ditambahkannya elemen tersebut dengan tujuan menambah minat belajar serta semangat mahasiswa dalam perkuliahan dan mengerjakan tugas.

Games typically allow players to restart or play again, making mistakes recoverable. This freedom to fail will enable students to experiment without fear and increases student engagement (Lee \& Hammer, 2011) .

Elemen gamifikasi dibuat sama persis seperti dengan game yang sedang berkembang sampai saat ini, yaitu berupa reward yang sangat berguna bagi mahasiswa [16]. Jika ingin menambah nilai atau menutup nilai yang kosong atau kurang pada tugas, mahasiswa dapat menggunakan point dari reward tersebut sehingga tugas dapat terselesaikan dengan baik dan maksimal. Selain itu, dosen juga dapat melihat mahasiswa yang sangat antusias mengikuti mata kuliah yang di ampuh dengan sistem peringkat reward gamifikasi, dimana yang teratas adalah mahasiswa yang memiliki point terbanyak.

Pemberian point juga memiliki aturan yakni, point yang diberikan harus melalui persyaratan yang diberikan oleh dosen dari mata kuliah yang di ampuh. Setiap dosen memiliki kriteria masing-masing dalam pemberian reward kepada mahasiswanya dan berbeda pastinya. Pada perguruan Tinggi Raharja terdapat media dalam menerapkanelemen gamifikasi tersebut, diantaranya ialah iDu (iLearning Education). iMe (iLearning Media), serta Rinfo (Raharja Info).

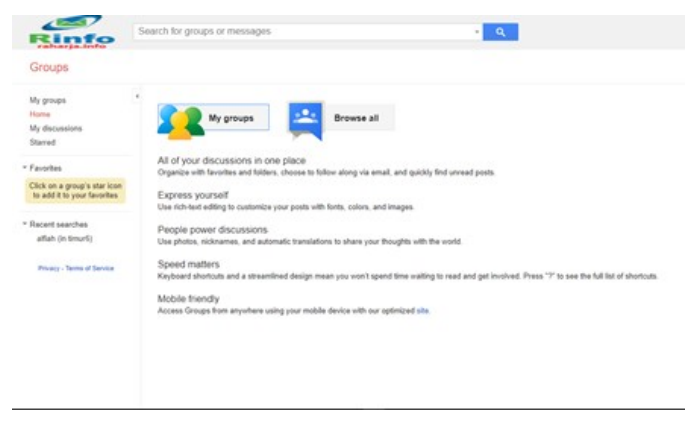

Gambar 1. Rinfo gr oups

DOI: https://doi.org/10.17509/e.v18i1.14697 
ambar di atas adalah gambaran kelompok Rinfo, dimana kelompok Rinfo dapat digunakan sebagai sarana komunikasi antara dosen dan siswa. Ada lebih dari satu grup rinfo dari setiap akun Rinfo .

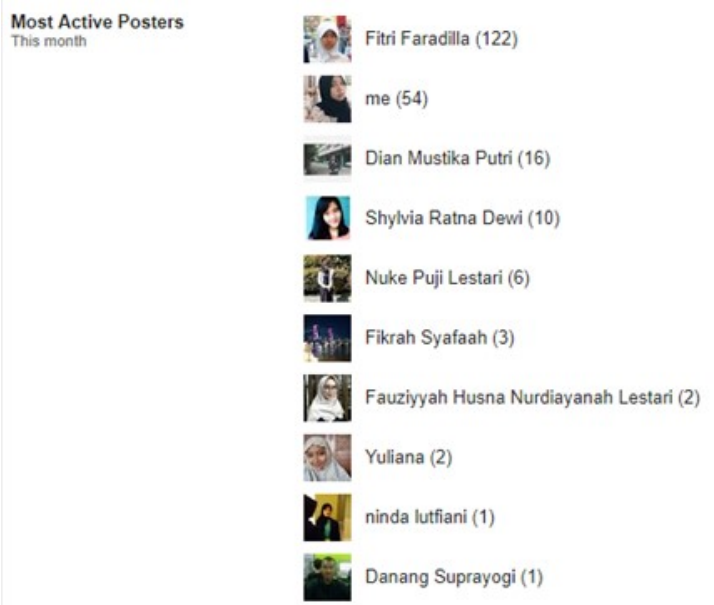

Gambar 2. Student activeness view on Rinfo Groups

Implementasi gamification dalam kelompok Rinfo, kita dapat menunjukkan aktivitas aktivitas dalam kelompok Rinfo, gambar di atas adalah sepuluh besar, atau kita dapat memanggil sebagai 10 (sepuluh) siswa paling aktif teratas di setiap grup. Ini tentu dapat memotivasi siswa dalam aktivitas berkomunikasi pada kelompok Rinfo.

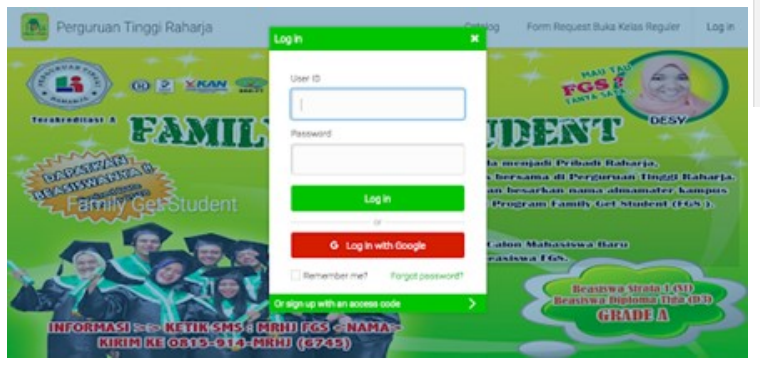

No. SK Akreditasi Ristekdikti : 34/E/KPT/2018
Gambar 3. login iDu (iLearning Education)

Gambar di atas adalah tampilan halaman iDu (iLearning Education) untuk masuk. Pengguna dapat login menggunakan nama pengguna dan kata sandi atau dapat login menggunakan SSO (Single Sign On) dengan memanfaatkan tombol google apps yang terintegrasi dengan email Rinfo.

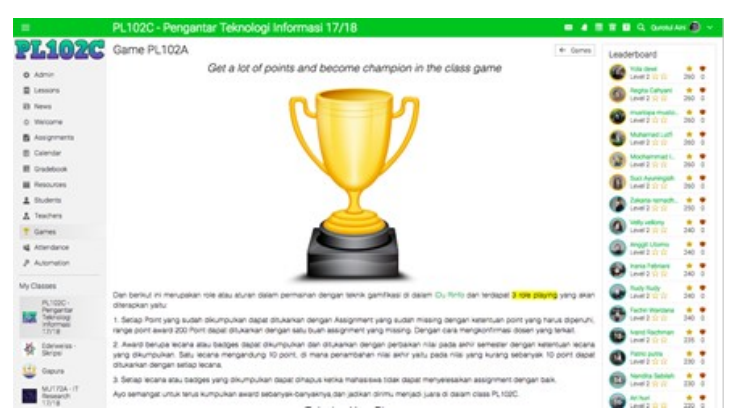

Gambar 4. Gamification on iDu (iLearning Education)

Gambar di atas adalah tampilan gamification yang ada di iDu (iLearning Education) bersama dengan aturan dan cara memainkannya.

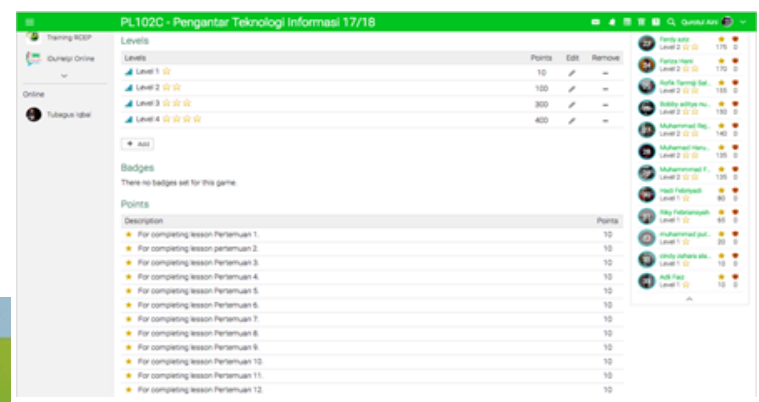

Gambar 5. view directives and gamification levels on iDu (iLearning Education) 
Tampilan pada gambar di atas adalah tingkat tampilan tingkat gamifikasi pada iDu (iLearning Education) bersama dengan poin yang diperoleh jika berhasil melewati level ini.

\section{iMe (iLearning Media)}

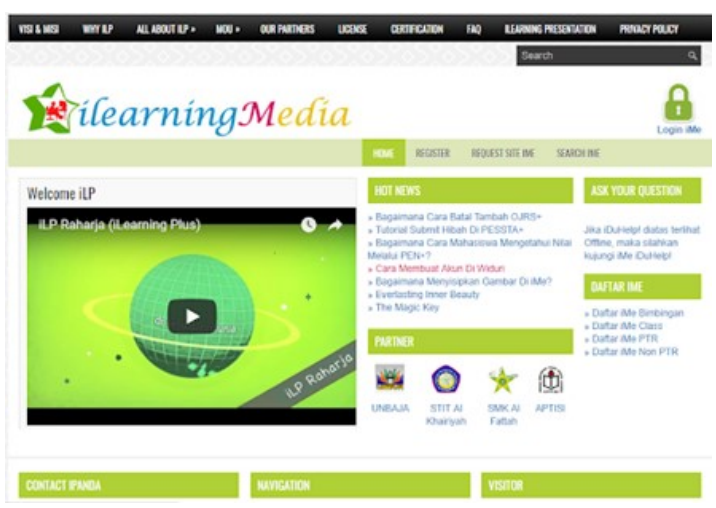

Gambar 6. login iMe (iLearning

$$
\text { Media) }
$$

Setelah gamification pada Rinfo dan iDu (iLearning Education), kali ini akan dibahas mengenai iMe (iLearning Media). Gambar di atas adalah tampilan login di iMe (iLearning Media) pada iMe gamifikasi atau iLearning Media dapat digunakan sebagai media dokumentasi yang baik untuk menangkap SC (Kontribusi Khusus) yang diperoleh siswa dan diabadikan di jendela masing-masing kelas

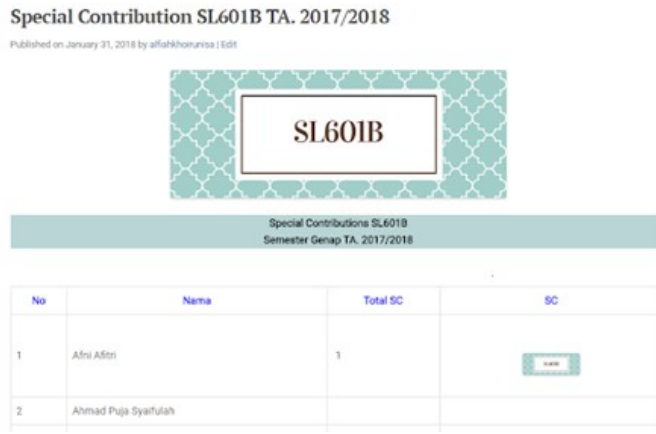

Gambar 7. Gamification on iMe (iLearning Media)

Gambar di atas adalah contoh dari sebuah gerai SC (Kontribusi Khusus) yang diberikan oleh fakultas kepada para siswanya.

Menurut Gabe Zichermann, dikutip oleh (Giang, 2013), penggunaan mekanik permainan meningkatkan kemampuan untuk mempelajari keterampilan baru sebesar $40 \%$. Pendekatan permainan mengarah ke tingkat komitmen dan motivasi pengguna yang lebih tinggi untuk kegiatan dan proses di mana mereka terlibat.

\section{SIMPULAN}

Dengan penerapan sistem pembelajaran gamification menggunakan media pembelajaran ilearning yang ada di Perguruan Tinggi Raharja seperti Rinfo, iDu (iLearning Education), dan iMe (iLearning Media), maka

DOI: https://doi.org/10.17509/e.v18i1.14697 
penulis dapat menyimpulkan sebagai berikut:

1. Adanya sistem gamification pada metode pembelajaran iLearning membuktikan proses pembelajaran dapat lebih interaktif dan lebih efisien, dosen juga dapat melihat siswa yang aktif di kelas.

2. Dengan penerapan sistem gamification membuat siswa menjadi lebih antusias dan termotivasi dalam belajar juga melakukan tugas-tugas yang diberikan.

3. Metode pembelajaran menjadi lebih menyenangkan dengan aplikasi sistem ini, tetapi tidak melupakan materi kuliah yang ada. Dengan demikian, ada keseimbangan antara mengajar dan belajar dan bermain dalam pembelajaran.

4. Membuat siswa lebih aktif di kelas dengan mengikuti proses pembelajaran.

5. Dengan meningkatnya minat siswa dalam proses pembelajaran sehingga perkembangan yang signifikan dapat dilihat dari kenaikan indeks prestasi siswa.

No. SK Akreditasi Ristekdikti : 34/E/KPT/2018
Dalam sebuah penelitian, tentu saja, memiliki keterbatasan dan apa yang akan dapat dilakukan di masa depan jika penelitian saat ini berjalan lancar. Jadi kelemahan dari penelitian ini adalah untuk menilai seberapa efektif penerapan metode gamification dalam manajemen pendidikan di Perguruan Tinggi Raharja sebagai langkah awal untuk mempersiapkan diri sebagai lembaga pendidikan yang berkontribusi untuk berjuang di era disruptif yang telah berkembang [20]. Ke depannya, penelitian ini akan mencoba menerapkan metode Gamification tidak hanya di Perguruan Tinggi tetapi juga di semua kampus yang ada di Indonesia.

\section{DAFTAR PUSTAKA}

Kardianawati, A., Haryanto, H., \& Rosyidah, U. (2016). PENERA-

PAN KONSEP GAMIFIKASI APPRECIATIVE PADA EMARKETPLACE UMKM.

Techno. Com, 15(4), 343-351.

Sagoro, E. M. (2016). Keefektifan Pembelajaran Kooperatif Berbasis Gamifikasi Akuntansi Pada Mahasiswa Non-Akuntansi. Jurnal Pendidikan Akuntansi Indonesia, 14(2).

Hamari, J., Koivisto, J., \& Sarsa, H. (2014). Does gamification 
work?--a literature review of empirical studies on gamification. In 2014 47th Hawaii international conference on system sciences (HICSS) (pp. 30253034). IEEE.

Supriyanto, S. (2017). Perancangan Penerapan Gamifikasi pada Media Informasi Ekowisata. In Seminar Nasional Aplikasi Teknologi Informasi (SNATI).

Rahardja, U. (2009). Artificial informatics. In Industrial Electronics and Applications, 2009. ICIEA 2009. 4th IEEE Conference on (pp. 3064-3067). IEEE.

Rahardja, U., Aini, Q., \& Khoirunisa, A. (2018). Monitoring Kinerja User Akuntan Menggunakan Dashboard Pada Web Based Accounting Online di Perguruan Tinggi. SATIN-Sains dan Teknologi Informasi, 4(2), 5862.

S. Publications, "DEVELOPMENT ASSESSMENT MODULE PORTFOLIO E -IMEI STUDENTS WITH LEARNING TO IMPROVE THE QUALITY OF," vol. 13, no. 8, pp. 35973606, 2016.

Rahardja, U., Tiara, K., \& Wijaya, R.

I. T. (2014). Penerapan Rinfo
Sebagai Media Pendukung Untuk Proses Pembelajaran Pada Perguruan Tinggi Raharja. CCIT Journal, 8(1), 101-115.

Warsito, A. B., Yusup, M., \& Rasdiana, E. (2015). Pemanfaatan RinfoDocs Sebagai Media Penyusunan Draft Laporan Dalam Proses Bimbingan TUgas Akhir Pada Perguruan Tinggi. CCIT Journal, 8(2), 34-44.

Rahardja, U., Handayani, I., \& Firmansyah, R. A. L. (2016). Penerapan SPB Online Menggunakan Rinfo Transformation Pada Bagian Pengadaan Perguruan Tinggi. CogITo Smart Journal, 2(1), 69-81.

Handayani, I., Aini, Q., \& Oktavyanti, Y. (2015). Penggunaan RinfoCal Sebagai Aplikasi Pengingat (Reminder) Kegiatan Akademik Pada Perguruan Tinggi. CCIT Journal, 9(1), 13-26.

Rahardja, U., Yusup, M., \& Aini, Q. (2014). Aplikasi Campus Learning System iOU (integrated Online Ujian) Dalam Mendukung Kegiatan iLearning Education (iDu) Pada Perguruan Tinggi. CCIT Journal, 7(3), 368383.

DOI: https://doi.org/10.17509/e.v18i1.14697 
Rahardja, U., \& Nurdin, I. (2014). Implementasi iMe (iLearning Media) Dalam Mendukung Sistem Pembelajaran iLearning Pada Perguruan Tinggi. CCIT Journal, 8(1), 167-182.

Rahardja, U., Aini, Q., \& Khoirunisa, A. (2017). Implementasi Business Intelligence Menggunakan Highchart pada Sistem Penilaian Absensi berbasis YII Framework. CSRID (Computer Science Research and Its Development Journal), 9(2), 115-124.

Handani, S. W., Suyanto, M., \& Sofyan, A. F. (2016). Penerapan Konsep Gamifikasi Pada ELearning Untuk Pembelajaran Animasi 3 Dimensi. Telematika, 9(1).

Rahardja, U., Aini, Q., Ariessanti, H. D., \& Khoirunisa, A. (2018). Pengaruh Gamifikasi pada iDu (iLearning Education) dalam Meningkatkan Motivasi Belajar Mahasiswa. Nusantara Journal of Computers and its Applications, 3(2).

Rahardja, U., Aini, Q., Azizah, N., \& Santoso, N. P. L. (2018). Efektivitas Akuntansi Online dalam Menunjang Proses Rekonsiliasi.
Nusantara Journal of Computers and its Applications, 3(2).

T. Journal and E. Februari, "No Title." Sunarya, P. A., Ariessanti, H. D., \& Yusup, M. iDU (iLEARNING EDUCATION) SEBAGAI MEDIA PELAKSANAAN TOEFL BERBASIS IBT (INTERNET BASED TEST) PADA PERGURUAN TINGGI.

Rahardja, U., Moein, A., \& Lutfiani, N. Leadership, Competency, Working Motivation and Performance of High Private Education Lecturer with Institution Accreditation B: Area Kopertis IV Banten Province. Man India, 97(24), 179-192.

Binarsatya, B. A., \& Sani, N. A. (2018). Rancang Bangun Aplikasi Game Avatar dengan Menerapkan Gamifikasi untuk Meningkatkan Minat Pengunjung Objek-Objek Bersejarah di Surabaya. Jurnal Teknik ITS, 7(1), 110-112.

Kristiadi, D., \& Mustofa, K. (2017). Platform Gamifikasi untuk Perkuliahan. IJCCS (Indonesian Journal of Computing and Cybernetics Systems), 11(2), 131142. 
Farozi, M. (2016). Rancang Bangun

Website Gamifikasi sebagai

Strategi Pembelajaran dan Evaluasi Hasil Belajar Mahasiswa.

SEMNASTEKNOMEDIA

ONLINE, 4(1), 4-2.

Kuswardayan, I., Herumurti, D., \& Santika, A. P. (2016). Rancang Bangun Aplikasi Edutainment untuk Anak SD dengan Teknik Gamifikasi Berbasis Octalysis dan Machinations Framework. Jurnal Teknik ITS, 5(2), A679A684.

Barber, M., Donnelly, K., Rizvi, S., \& Summers, L. (2013). An avalanche is coming. Higher Education and the revolution ahead, 73.

Pesare, E., Roselli, T., Corriero, N., \& Rossano, V. (2016). Gamebased learning and gamification to promote engagement and motivation in medical learning contexts. Smart Learning Environments, 3(1), 5 .

Rahardja, U., Handayani, I., \& Ningrum, A. A. (2018). Pemanfaatan Sistem iMe Berbasis WordPress sebagai Official Site RCEP pada Perguruan Tinggi. Creative Information Technology Journal, 4(3), 207-219. 